\title{
Source process of the 2011 off the Pacific coast of Tohoku Earthquake inferred from waveform inversion with long-period strong-motion records
}

\author{
Kunikazu Yoshida ${ }^{1}$, Ken Miyakoshi ${ }^{1}$, and Kojiro Irikura ${ }^{2}$ \\ ${ }^{1}$ Geo-Research Institute, 4-3-2 Itachibori, Nishi-ku, Osaka 550-0012, Japan \\ ${ }^{2}$ Aichi Institute of Technology, 1247 Yachigusa, Yakusa, Toyota, Aichi 470-0392, Japan
}

(Received April 15, 2011; Revised June 27, 2011; Accepted June 28, 2011; Online published September 27, 2011)

\begin{abstract}
We have investigated the rupture process of the 2011 off the Pacific coast of Tohoku Earthquake using a multitime-window linear waveform inversion method using long-period strong-ground motion data. From the record section of the long-period motion of the 3 phases, it is indicated that the rupture process mainly consists of the 3 stages. We have assumed a single planar fault model of $468 \mathrm{~km}$ long in strike and $228 \mathrm{~km}$ wide in dip. The seismic moment of this earthquake was estimated to be $4.3 \times 10^{22} \mathrm{~N} \mathrm{~m}\left(M_{\mathrm{w}} 9.0\right)$. The inverted slip distribution shows a large asperity with a maximum slip of about $47 \mathrm{~m}$ which is located on the shallower part of the fault plane. The rupture process is divided into three stages: a first stage with moderate slip; a second stage with large and long-duration slip in the shallow part of the fault; and a third stage with relatively small and short-duration slip in the southern part of the fault. The feature of the ground motion suggested from the record section is well represented by the peak moment rate distributions, rather than the slip distributions. The rupture velocity is around $3-4 \mathrm{~km} / \mathrm{s}$ in the first and third stages, while rupture progression was suspended for a while before the rupture of the asperity.
\end{abstract}

Key words: 2011 Tohoku Earthquake, long-period ground motion, strong motion, source process, peak moment rate distribution.

\section{Introduction}

On 11 March 2011, the Tohoku Earthquake of $M_{\mathrm{W}} 9.0$ (Japan Meteorological Agency) struck the Tohoku region, Japan, and generated a huge tsunami. Historical and seismic records indicate that interplate earthquakes with magnitudes of about 7.5 have occurred repeatedly around the hypocenter of this event with a recurrence interval of about 37 years (the Headquarters for Earthquake Research Promotion, MEXT, Japan, 2001). Recent studies have pointed out that the magnitude of the AD 869 Jogan earthquake, which occurred around the off coast of Miyagi area, was greater than $M_{\mathrm{w}} 8.4$ (e.g., Satake et al., 2008). The 2011 Tohoku Earthquake (the 2011 off the Pacific coast of Tohoku Earthquake named by JMA) is the first $M 9$ earthquake to have been recorded by many near-field strongmotion stations. During previous historical $M 9$-class earthquakes (e.g., 2004 Sumatra, 1964 Alaska, 1960 Chile), few strong-motion seismometers near the source region were operated. It is important to discuss whether the asperity estimated from waveform inversion using long-period strong motion is the same as those using the tsunami, and to discuss the relationship between large slip area (asperities) expected to excite tsunami, and strong-motion generating areas (SMGAs).

In this study, we first investigate the characteristics of the

Copyright (c) The Society of Geomagnetism and Earth, Planetary and Space Sciences (SGEPSS); The Seismological Society of Japan; The Volcanological Society of Japan; The Geodetic Society of Japan; The Japanese Society for Planetary Sciences; TERRAPUB.

doi:10.5047/eps.2011.06.050 rupture from the observed seismograms directly. Then, we estimate the source process using the long-period strongmotion waveform data in the near-field region of the event.

\section{Observed Seismograms}

A large number of strong motion records were obtained during the mainshock. In this section, we use the data obtained from the strong-motion seismometers of F-net and KiK-net (Aoi et al., 2004; Okada et al., 2004) operated by the National Research Institute for Earth Science and Disaster Prevention. From the KiK-net stations, we chose stations located on relatively hard rock to avoid local site effects.

Due to the large number of seismometers, it is possible to build up dense record sections. Record sections of bandpass filtered velocity seismograms are displayed along latitude in Fig. 1. Two significant phases (1 and 2) originating around the epicenter $\left(38.5^{\circ} \mathrm{N}\right)$ are identified. The origin of Phase 2 seems to be slightly north of that of Phase 1 . Phase 2 propagated in both directions, north and south, judging from the decrease in its amplitude. The apparent pulse width of Phase 2 coming around the epicenter is about 30 40 seconds. In the station south of $37^{\circ} \mathrm{N}$, the amplitude of this phase does not attenuate despite the increase in source distance. The apparent pulse width of the phase (about $20 \mathrm{~s}$ ) is shorter than that of Phase 2 (about 30-40 s). Thus, it is suggested that this wave is another phase excited by another source around $37^{\circ} \mathrm{N}$ (Phase 3). These origins of the phases are discussed in Section 4. 


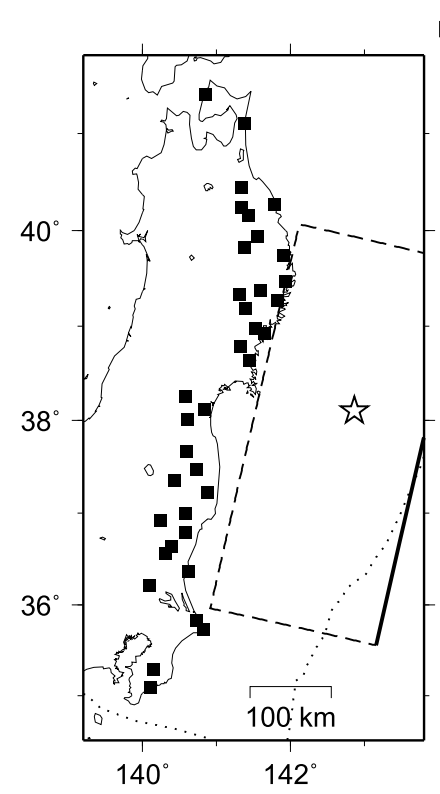

Pass band: 100 - 20 s, EW comp. $\begin{array}{llllll}0 & 60 & 120 & 180 & 240 & 300\end{array}$
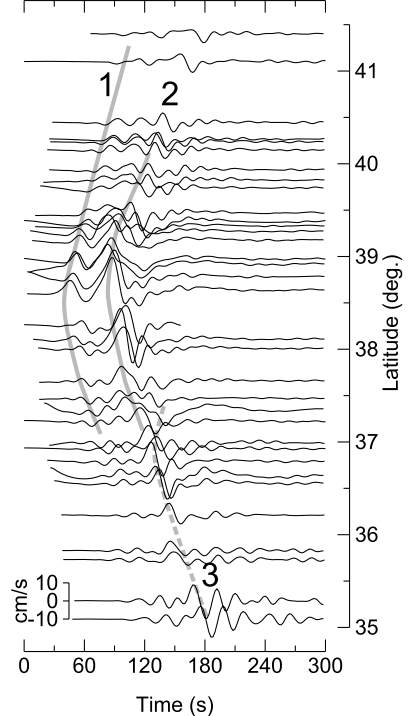

Fig. 1. (Left) Map showing F-net and KiK-net stations (solid square) and the assumed fault plane (rectangle). The star shows the epicenter determined by JMA. (Right) Band-pass filtered velocity seismograms of the horizontal EW component. Pass-bands are 0.01-0.05 Hz (100-20 s). The waveforms are pasted up with the delay time from the origin time.

\section{Inversion of the Source Process}

We used the strong-motion data obtained from 37 stations of F-net and KiK-net, and 1 station (MYR, Sasatani et al., 2002) of Hokkaido University (Fig. 2). These stations are located on relatively hard rock. The velocity-type broadband seismometers used for F-net (VSE-355G3) and MYR (VS3, Muramatsu et al., 2001) are very capable of recording very long-period components excited by this $M 9$ earthquake.

The data were windowed for $300 \mathrm{~s}$, starting at $P$-wave arrival time, and band-pass filtered between periods of $200 \mathrm{~s}$ to $20 \mathrm{~s}(0.005-0.05 \mathrm{~Hz})$ for waveform inversion. The accelerograms obtained from the KiK-net were integrated into ground velocities with a sampling time of $4 \mathrm{~s}$.

We assumed a single fault plane for the waveforminversion analysis. The fault size is assumed to be $468 \mathrm{~km}$ long in strike and $228 \mathrm{~km}$ wide in dip, referring to the aftershock distribution. We assume $\mathrm{N} 193^{\circ} \mathrm{E}$ and $10^{\circ}$ as the strike and dip angles, respectively, referring to the JMA CMT solution. The rupture starting point is located at the hypocenter determined by JMA: $38.103^{\circ} \mathrm{N}, 142.861^{\circ} \mathrm{E}, 23.7 \mathrm{~km}$.

Theoretical Green's functions are calculated using the discrete wavenumber method (Bouchon, 1981) and the reflection/transmission-coefficient matrix method (Kennet and Kerry, 1979) using a stratified medium. The velocitystructure model proposed by Wu et al. (2008, 2009) for the waveform inversion of the 1979 and 2005 Miyagi-oki earthquake was used for calculating the theoretical Green's functions (Fig. 3). We use an identical structure model for all stations, because the stations used in the inversion are located on almost hard rock, so it is expected that the observed seismograms are less affected by local site effects in the long-period range.

We use a multi-time-window linear waveform-inversion

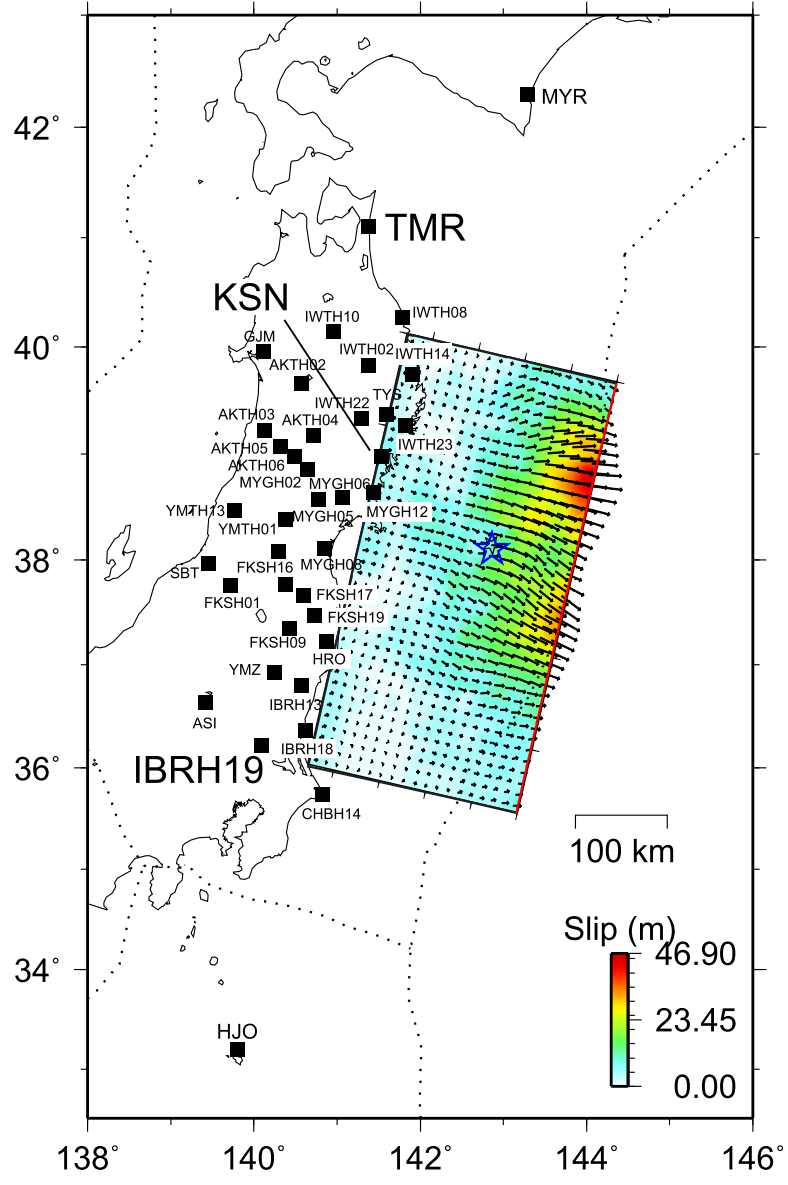

Fig. 2. Projection of the final slip distribution on the map. The star and squares indicate the rupture starting point and the strong-motion stations that are used for the inversion. The dotted line shows plate boundaries (Bird, 2003).

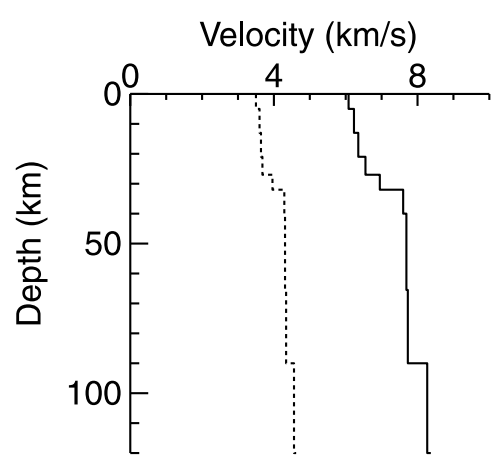

Fig. 3. Velocity-structure model used in the inversion analysis (Wu et al., 2008, 2009).

procedure (e.g., Hartzell and Heaton, 1983) in which the moment-release distribution is discretized in both space and time. For discretization in space, we divide the fault plane into 39 in the strike direction and into 19 in the down-dip direction (making a total of 741 subfaults over an area of $12 \mathrm{~km} \times 12 \mathrm{~km}$ ). We use 8 smoothed ramp functions with a duration of $16 \mathrm{~s}$ separated by 8 -s intervals to represent the slip history of each subfault. The triggering front of the first-time-window propagates at a constant velocity, and the multi-time-window analysis allows a variable rupture velocity and slip duration in an inverted rupture model by 
weighted time windows. To suppress instability or excessive complexity, a smoothing constraint is introduced to reduce differences in moment release values close in space. The smoothing constrained parameter used in the inversion was determined to choose the solution with a total slip which agrees with that expected from the geodetic data (e.g. $24 \mathrm{~m}$ at off coast of Miyagi, by Sato et al., 2011). Nonnegative constraints (Lawson and Hanson, 1974) to limit the rake-angle variation are also adopted. The rake angles are allowed to vary within $45^{\circ}$ centered at $90^{\circ}$. We use the first time window triggering velocity (FTWTV) as $2.5 \mathrm{~km} / \mathrm{s}$, and the rupture velocity will be discussed in Section 4 .

\section{Result and Discussion}

In the total slip distribution, we can see a large asperity area with a large slip in the shallow part of the fault plane. The asperity size is about $300 \mathrm{~km} \times 100 \mathrm{~km}$, and the slip on the asperity is about 20 to $47 \mathrm{~m}$ (Fig. 4). The slip vectors indicate an almost pure dip-slip fault mechanism (Fig. 2). The total moment release is $4.3 \times 10^{22} \mathrm{~N} \mathrm{~m}$ $\left(M_{\mathrm{w}} 9.0\right)$. This moment is similar to the seismic moment of $3.43 \times 10^{22} \mathrm{~N} \mathrm{~m}$ which is derived from GPS data (Ozawa $e t$ al., 2011). Synthetics calculated from the estimated rupture process are compared with the observed data in Fig. 5. The overall matching between synthetics and observation is very good.

Slip models by tsunami inversion are proposed by Satake

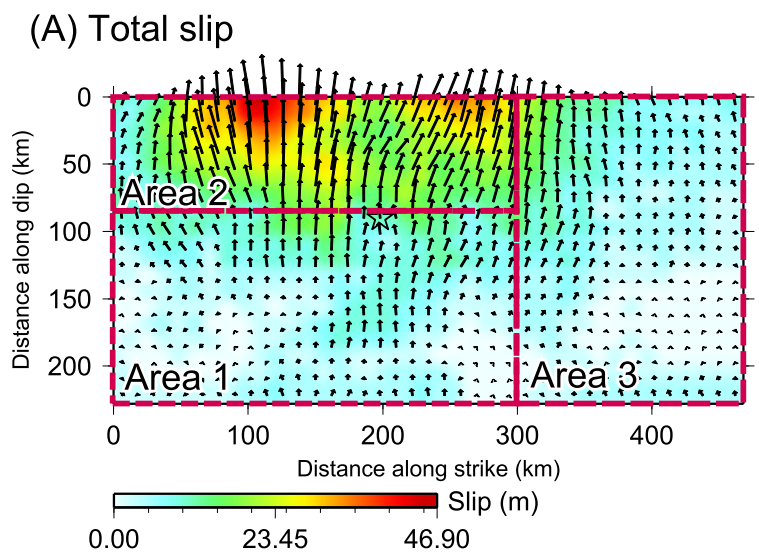

(B) Peak moment rate

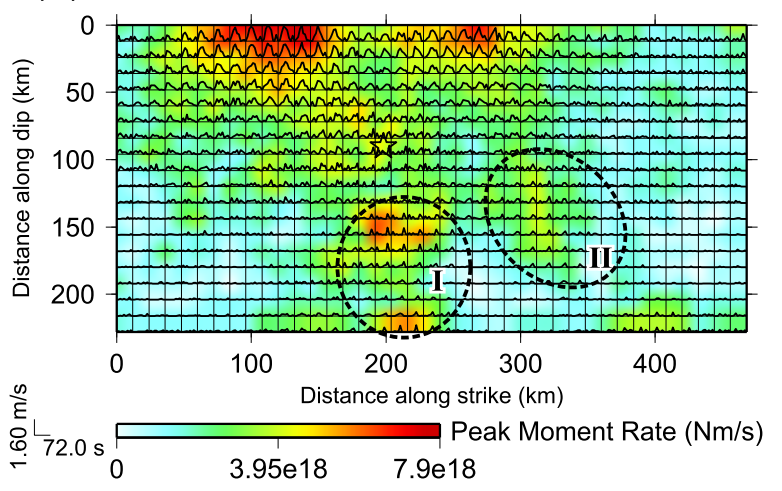

Fig. 4. Upper: Distributions of coseismic slip obtained for the 2011 Tohoku Earthquake. The star indicates the rupture starting point. The rectangle represented by the dashed line indicates 3 areas, Area 1, 2, and 3 denoted in the text. Lower: Distributions of peak moment rate together with the slip rate function at each subfault.

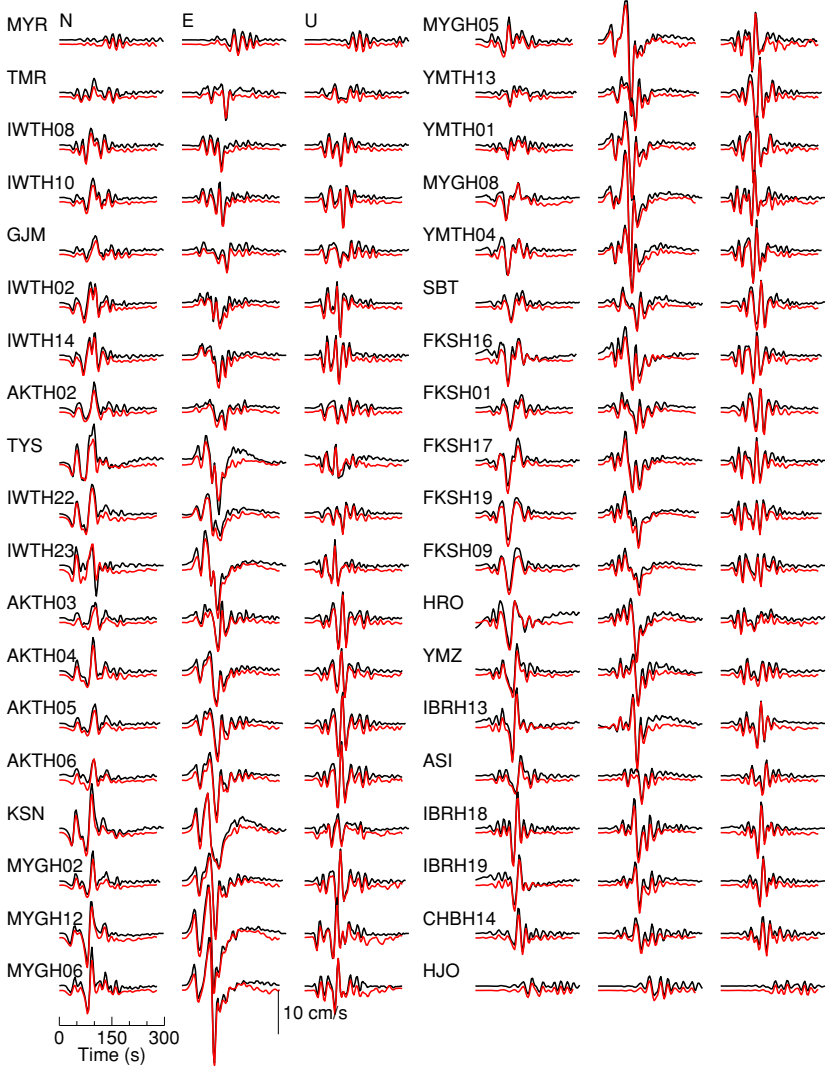

Fig. 5. Comparison of observed (black) and synthetic (red) velocity waveforms. The origin of the time axis is the arrival of the $P$-wave. The pass-band of the band-pass filter is from $200 \mathrm{~s}$ to $20 \mathrm{~s}$. Note that the order of the records is from north to south.

et al. (2011). The overall slip patterns and the average slip in the shallow part of the fault along the trench in this study are nearly the same as their results (the maximum slip of about $30 \mathrm{~m}$ ).

The time progression of the rupture (Fig. 6) shows that the source process of the earthquake consists of 3 rupture stages. In order to explain the contributions to the waveforms in the three stages, we divided the source model into Areas 1,2 and 3: the deeper part of the fault, the shallower asperity area of the northern part of the fault, and the southern part of the fault (Fig. 4). In the first stage of the fault rupture, moderate moment-rate areas are found at the southern and deeper side of the rupture starting point (the frame of 15-30 s). The rupture front also reached the shallower part of the fault (asperity area) at about $40 \mathrm{~s}$ after the rupture initiation, and rupture progression seems to be suspended in that part (the frame of $30-45 \mathrm{~s}$ in Fig. 6). At 45-60 s after the rupture initiation, the second stage of the rupture started in the shallower part of the fault (the asperity area, Area 2 in Fig. 4(A)). The asperity area, with a length of about $300 \mathrm{~km}$, simultaneously began to rupture with a high moment rate, and the rupture continued for 30-40 s (the frames of 45$60 \mathrm{~s}$ to $75-90 \mathrm{~s})$. Moderate moment was released in the deeper part of the fault (the frame of 75-90 s in Fig. 6, I in Fig. 4(B)). After the moment rate in the asperity area declined, the third stage of the rupture seemed to be triggered. After that, the rupture mainly progressed to the southern part of the fault (the frame of 90-105 s), and the deeper part 

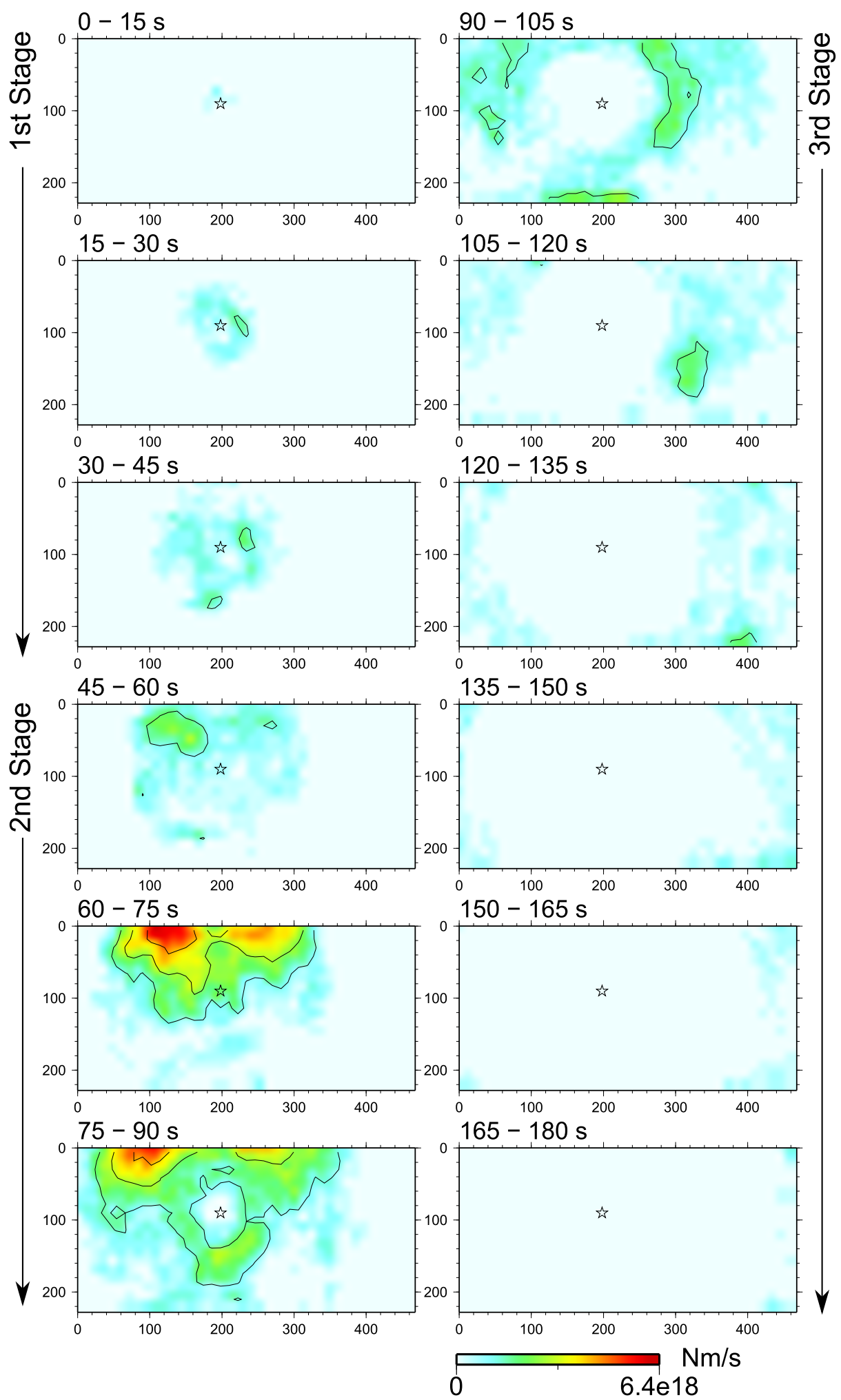

Fig. 6. Snapshots of the rupture progression for every $15 \mathrm{~s}$. The star indicates the rupture starting point. The numbers at the top of each frame show the time after the start of the rupture. Rupture stages denoted in the text are also shown.

of the fault (the frames after 105-120 s). In the frames of 90-105 s and 105-120 s, some moderate moment-rate areas in the southern part of the fault plane (Area 3 in Fig. 4(A)) are recognized. The rupture of these areas radiated shortperiod components with a short pulse width of moment-rate functions (II in Fig. 4(B)). The total source duration time is about $200 \mathrm{~s}$.
Phases 1, 2 and 3 identified from the record sections (Fig. 1) correspond to the rupture stages. We examine the contribution of slips in three areas on the fault plane to waveforms at 3 stations (Fig. 7). In the first stage of the rupture, the rupture occurred around the rupture starting point. Figure 7 shows that the first arrival waves (Phase 1) come from Area 1. 


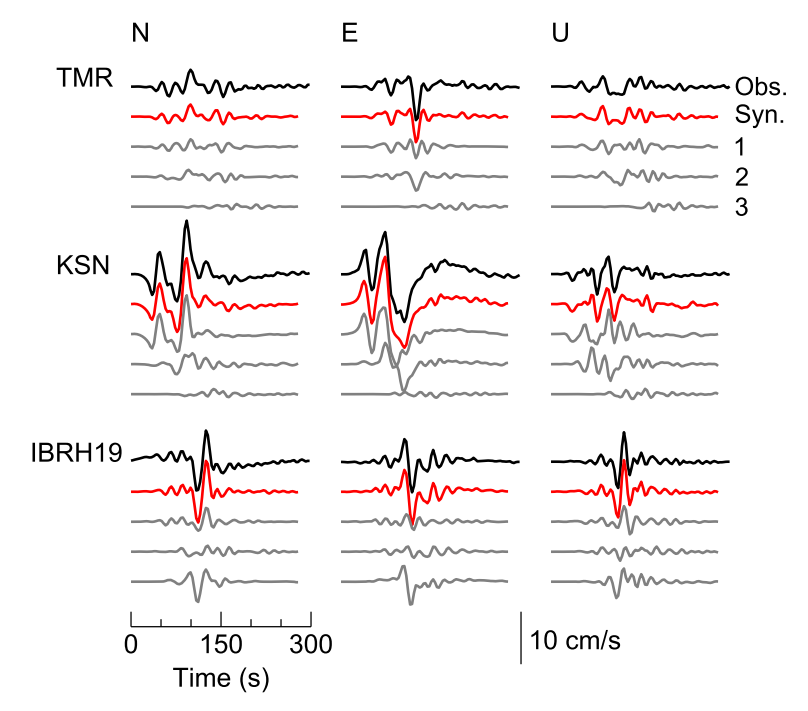

Fig. 7. Comparison of the contribution of the slip at each area shown in Fig. 4 to the waveforms at TMR, KSN and IBRH19. Traces 1, 2, and 3 are the synthetics calculated from Area 1, 2, and 3 of the fault model (Fig. 4).

Phase 2 (around $100 \mathrm{~s}$ in Fig. 7) is expected to be generated during the second stage of the rupture. The synthetics calculated from Area 2 (the asperity area) explain the largest waves observed at the northern station (e.g. TMR). At KSN, Phase 2 consists of the superposition of the waves calculated from Areas 1 and 2 with similar amplitudes. The pulse width coming from Area 1 is short $(\sim 20 \mathrm{~s})$, whilst that from Area 2 is long (>30 s). The high moment rate on the deeper part (I in Fig. 4(B)) just after the rupture of the asperity (frame $75-90 \mathrm{~s}$ in Fig. 6) also contributes to Phase 2, which is overlapping on the seismic waves coming from Area 2.

Phase 3, which is the largest wave at the southern station (e.g. IBRH19), is not explained by the synthetics calculated from Area 1 or 2. The synthetics calculated from Area 3, which is active in the third stage, explain Phase 3. Although there is no clear slip in the total slip distribution in Area 3, a moderate peak moment-rate area (II in Fig. 4(B)) is found in Area 3.

The distribution of the peak moment rate indicates some strong peak areas of the moment-rate functions. Two high peak moment-rate areas are located on the deeper side of the rupture starting point (I) and one moderate peak area is recognized on the southern part of the fault plane (II). The strong motion-generating area derived by EGF modeling (Kurahashi and Irikura, 2011) agrees well with the peak moment-rate distribution, rather than the slip distribution. The moment-rate function gives far-field displacement waveforms of $P$ and $S$ waves (e.g. Aki and Richards, 2002). Thus, ground motions reflect moment rate rather than slip distribution; in particular, short-period motions depend on the peak moment-rate distribution.

Figure 8 shows the moment rate as a function of time and distance from the rupture starting point in order to investigate the rupture velocity. The apparent rupture velocity can be found by tracing the peak of the moment rate. The first time window triggering time $(F T W T V=2.5 \mathrm{~km} / \mathrm{s})$ is

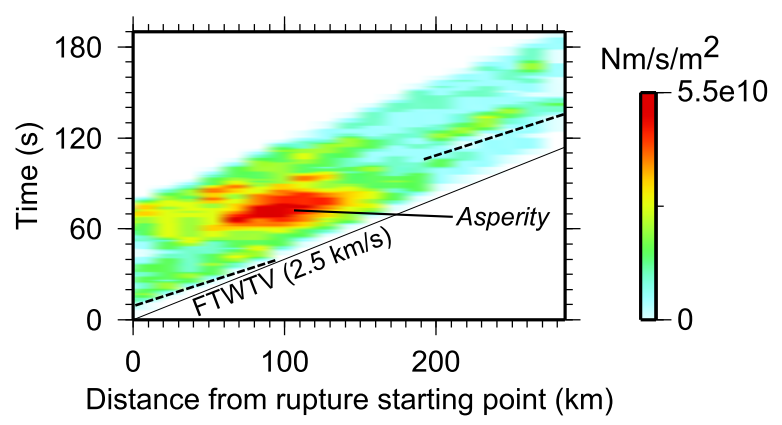

Fig. 8. Moment rate as a function of time and distance from the rupture starting point. The moment rate at each mesh is shown with an interval of $2.5 \mathrm{~s}$ in time and $15 \mathrm{~km}$ in distance. FTWTV of $2.5 \mathrm{~km} / \mathrm{s}$ (no moment releases before this line) is indicated by the dotted line. Dashed lines show the apparent rupture velocity of $3.5 \mathrm{~km} / \mathrm{s}$.

also plotted on the same figure. As shown in Fig. 6, the rupture of the asperity is not smoothed. In contrast to the complicated rupture of the asperity, the rupture in the first (0-45 s from the rupture start) and third (90-180 s) stages progressed in velocities of $3-4 \mathrm{~km} / \mathrm{s}$. This rupture velocity is similar to the $S$-wave velocity of the lower crust or upper mantle (3.68-4.29 km/s, Fig. 3). The rupture front reaches the edge of the fault (about $300 \mathrm{~km}$ ) at about $130 \mathrm{~s}$ after the rupture start. As a result of the heterogeneous rupture propagation, the average rupture velocity of the entire fault is about $2.2 \mathrm{~km} / \mathrm{s}$, which is obviously slower than 2.6$3.0 \mathrm{~km} / \mathrm{s}$ that is expected from the $S$-wave velocity (Geller, 1976). The average rupture velocity obtained from the inversion is similar to that obtained from the 2004 SumatraAndaman earthquake $(2.2 \mathrm{~km} / \mathrm{s}$, Vallée, 2007). The rupture velocities during the first and third stages are similar to those of the 1978 and 2005 Miyagi-oki earthquakes $\left(M_{\mathrm{w}} 7.5\right.$ and 7.1). For example, Wu et al. $(2008,2009)$ used FTWTV as 3.2 and $3.4 \mathrm{~km} / \mathrm{s}$ for their inversions of the rupture processes of the 1978 and 2005 events, respectively.

\section{Conclusions}

We have investigated the rupture process of the 2011 Tohoku Earthquake by examining the long-period components of the near-source region strong-motion waveforms and by multi-time-window linear-waveform inversion using the long-period (20-200 s) strong-motion records. The record section of the long-period strong ground motion implies that the rupture process consists of 3 stages. The inverted-source process model shows that a large asperity (about $300 \mathrm{~km} \times 100 \mathrm{~km}$ ) located on the shallower part of the fault was estimated, and maximum slip is about $47 \mathrm{~m}$. This source model with a shallow large asperity is consistent with the tsunami source model (Satake et al., 2011). The rupture process is divided into three stages: the first stage with moderate slip in the deeper area of the northern part of the fault; the second stage with large and longduration slip in the shallow area of the northern part of the fault (the asperity area); and the third stage with the rupture of the southern part of the fault. The feature of the ground motion suggested from the record section is wellrepresented by the peak moment-rate distributions, rather than the slip distributions. The rupture velocity is around 
$3-4 \mathrm{~km} / \mathrm{s}$ in the first and third stages, while rupture progression is suspended for a while before the rupture of the asperity. As a result of the heterogeneous rupture propagation, the average rupture velocity in the entire fault is about $2.2 \mathrm{~km} / \mathrm{s}$.

Acknowledgments. We thank the National Research Institute for Earth Science Disaster Prevention and Hokkaido University to provide the strong-motion data. The clarity and completeness of the article was improved by reviews from Dr. Yoshiaki Shiba and an anonymous reviewer. Many of the figures in this paper were produced using GMT (Wessel and Smith, 1998).

\section{References}

Aki, K. and P. G. Richards, Quantitative Seismology, second edition, 700 pp, University Science Books, Sausalito, 2002.

Aoi, S., T. Kunugi, and H. Fujiwara, Strong-motion seismograph network operated by NIED: K-NET and KiK-net, J. Jpn. Assoc. Earthq. Eng., 4, 65-74, 2004.

Bird, P., An updated digital model of plate boundaries, Geochem. Geophys. Geosyst., 4, 1027, 2003.

Bouchon, M., A simple method to calculate Green's functions for elastic layered media, Bull. Seismol. Soc. Am., 71, 959-971, 1981.

Geller, R. J., Scaling relations for earthquake source parameters and magnitudes, Bull. Seismol. Soc. Am., 66, 1501-1523, 1976.

Hartzell, S. H. and T. H. Heaton, Inversion of strong ground motion and teleseismic waveform data for the fault rupture history of the 1979 Imperial Valley, California, earthquake, Bull. Seismol. Soc. Am., 73, 1553-1583, 1983.

Kennet, B. L. N. and N. J. Kerry, Seismic waves in a stratified half space, Geophys. J. R. Astron. Soc., 57, 557-583, 1979.

Kurahashi, S. and K. Irikura, Source model for generating strong ground motions during the 2011 off the Pacific coast of Tohoku Earthquake, Earth Planets Space, 63, this issue, 571-576, 2011.

Lawson, C. L. and R. J. Hanson, Solving Least Square Problems, PrenticeHall, Inc., New Jersey, 1974.

Muramatsu, I., T. Sasatani, and I. Yokoi, Velocity-type strong-motion seismometer using a coupled pendulum: Design and performance, Bull.
Seismol. Soc. Am., 91, 604-616, 2001.

Okada, Y., K. Kasahara, S. Hori, K. Obara, S. Sekiguchi, H. Fujiwara, and A. Yamamoto, Recent progress of seismic observation networks in Japan-Hi-net, F-net, K-NET and KiK-net—, Earth Planets Space, 56, xv-xxviii, 2004.

Ozawa, S., T. Nishimura, H. Suito, T. Kobayashi, M. Tobita, and T. Imakiire, Coseismic and postseismic slip of the 2011 magnitude-9 TohokuOki earthquake, Nature, 475, 373-376, 2011.

Sasatani, T., T. Maeda, K. Yoshida, N. Morikawa, M. Ichiyanagi, Y. Motoya, and M. Kasahara, Strong-motion Observation in Hokkaido with Broadband, Velocity-type Seismometers, Geophys. Bull. Hokkaido Univ., 65, 335-345, 2002.

Satake, K., Y. Namegaya, and S. Yamaki, Numerical simulation of the AD 869 Jogan tsunami in Ishinomaki and Sendai plains, Ann. Rep. Active Fault Paleoearthq. Res., Geological Survey of Japan/AIST, 8, 71-89, 2008.

Satake, K., S. Sakai, Y. Fujii, M. Shinohara, and T. Kanazawa, Tsunami source of 2011 Tohoku Earthquake, Kagaku, 81, 407-410, 2011.

Sato, M., T. Ishikawa, N. Ujihara, S. Yoshida, M. Fujita, M. Mochizuki, and A. Asada, Displacement above the hypocenter of the 2011 Tohokuoki Earthquake, 332, 1395, 2011.

The Headquarters for Earthquake Research Promotion, MEXT, Japan, Long-term evaluation of the Miyagi-oki earthquake, http://www.jishin.go.jp/main/index.html, 2001.

Vallée, M., Rupture properties of the giant Sumatra Earthquake imaged by empirical Green's function analysis, Bull. Seismol. Soc. Am., 97, S103S114, 2007.

Wessel, P. and W. H. F. Smith, New, improved version of the Generic Mapping Tools released, Eos Trans. AGU, 79, 579, 1998.

Wu, C., K. Koketsu, and H. Miyake, Source processes of the 1978 and 2005 Miyagi-oki, Japan, earthquakes: Repeated rupture of asperities over successive large earthquakes, J. Geophys. Res., 113, B08316, 2008.

Wu, C., K. Koketsu, and H. Miyake, Correction to "Source processes of the 1978 and 2005 Miyagi-oki, Japan, earthquakes: Repeated rupture of asperities over successive large earthquakes", J. Geophys. Res., 113, B08316, 2009.

K. Yoshida (e-mail: yoshida@geor.or.jp), K. Miyakoshi, and K. Irikura 